\title{
"SOU O MUNDO, SOU MINAS GERAIS": O SER DA EXPERIÊNCIA EM "PARA LENNON E MCCARTNEY"
}

\author{
"SOU O MUNDO, SOU MINAS GERAIS": THE BEING OF \\ EXPERIENCE IN "PARA LENNON E MCCARTNEY"
}

COELHO, Rafael Senra ${ }^{1}$

\begin{abstract}
RESUMO: A canção "Para Lennon e McCartney" imagina um diálogo entre músicos latino americanos e anglo-saxões. Os dois cantores citados no título tornam-se uma metonímia de toda a indústria musical do eixo Europa/EUA. Nessa composição, a condição simultânea rural e urbana que compõe o espaço da periferia permite que o sujeito da experiência persista na modernidade. A voz do narrador experiente confronta todo o projeto de identidade supostamente coerente da metrópole, baseado no acúmulo de informação.
\end{abstract}

PALAVRAS-CHAVE: Identidade, Globalização, Experiência, Música Popular.

\begin{abstract}
The song "Para Lennon e McCartney" imagines a dialogue between Latin American and Anglo-Saxon musicians. The two singers mentioned in the title symbolize the entire music industry from Europe and United States. In this composition, the simultaneous rural and urban condition of poor countries allows the permanence of the experienced person in modernity. The voice of the experienced narrator confronts the coherent identity project from people in North metropolis, based in accumulation of information.
\end{abstract}

KEYWORDS: Identity, Globalization, Experience, Popular Music.

Entre as décadas de 1960 e 70, o movimento conhecido como Clube da Esquina conseguiu projeção de público e crítica, e se tornou o que talvez seja o mais expressivo coletivo musical do Estado de Minas Gerais. Simultaneamente a movimentos como a Tropicália na Bahia, os músicos mineiros sedimentaram um estilo calcado em procedimentos antropofágicos, que

\footnotetext{
${ }^{1}$ Doutor em Letras pela Universidade Federal de Juiz de Fora. Bolsista PNPD/CAPES na Universidade Federal de Viçosa - UFV.
} 


\section{1 jangäada}

envolviam a mescla de influências tanto da música brasileira quanto da estrangeira - sobretudo a música popular daquele período.

Milton Nascimento, que era o centralizador das atividades do Clube, grava em seu quarto disco (Milton, de 1970) a composição "Para Lennon e McCartney", que, tanto na letra quanto nos arranjos, assinalava um amadurecimento de sua proposta e a costura de uma elaboração autoral mais arrojada. No ano seguinte, o célebre disco Clube da Esquina (1971) se tornaria o ápice dessa busca por uma assinatura sonora e estética original.

Em 1969, nos arredores da famosa esquina do Clube (no cruzamento entre as ruas Paraisópolis e Divinópolis, bairro Santa Teresa, Belo Horizonte), "Para Lennon e McCartney" nascia despretensiosamente: em meio à uma macarronada feita na casa da família Borges, os letristas Márcio Borges e Fernando Brant arriscaram alguns versos para a melodia que o adolescente Lô Borges executava repetidamente no piano:

Na saleta de piano, Lô convocou a mim e ao Fernando para ouvirmos um tema que acabara de compor ali na hora, no meio daquela confusão de irmãos, amigos e cervejada. Todos os que estavam por perto na hora se acercaram do piano, para ouvir o tema de Lô. Então, depois de executá-lo por diversas vezes, a ponto de todos estarmos cantarolando os "lá-lá-lás" em uníssono com ele, sem erros, Lô parou de tocar e nos propôs:

— Então? Vocês dois não querem meter uma letra nisso não?

— Só se for agora — respondeu Fernando.

— Qual é o tema que você pensou pra ela? — perguntei.

- Na verdade, eu estava pensando na parceria do John e do Paul... nas parcerias, né. A gente aqui, também fazendo as nossas... e eles nunca vão saber. Mas pode ser outra coisa qualquer que vocês sentirem - Lô se apressou em dizer (BORGES, 2004, p. 189).

Na época um adolescente de 16 anos, Lô não iniciou apenas o processo da composição melódica. De acordo com o relato de seu irmão Márcio mencionado acima, ele sugere também a temática lírica da canção, inspirado em John Lennon e Paul McCartney, líderes da banda The Beatles. Sua ideia é facilmente compreendida ao considerarmos que, para boa parte dos jovens 
brasileiros da época, a emergência da cultura de massa estrangeira começava a se fazer sentir. A chamada beatlemania foi um dos principais braços da "Grande Invasão Britânica" - como foi batizado o movimento que exportou grupos roqueiros da Inglaterra no cenário pós-segunda guerra mundial. Nessa grande onda de grupos roqueiros, as canções eram o carro forte, mas paralelo a elas havia todo um universo de consumo que envolvia moda, filosofia, comportamento, uso de drogas, e muito mais.

"No decorrer de 1965, só um ermitão poderia estar alheio ao fenômeno Beatles. Não havia um jovem que não soubesse seus nomes e sua história. Liverpool e Hamburgo eram citadas como um católico citaria Fátima ou Lourdes", disse Márcio Borges, resumindo bem o impacto das canções do grupo naquela época (BORGES, 2004, p.115). Em diferentes espaços, o espírito daquele tempo emanava o que mais tarde seria batizado como contracultura. Mas quem ditava a trilha sonora consumida mundialmente eram os grandes centros, maiores exportadores de bens culturais. Os artistas que alcançavam o espaço da rede de consumo não eram necessariamente os mais talentosos ou universais, mas os que atendiam aos desígnios da grande indústria - situada no eixo anglo-saxão entre Estados Unidos e Inglaterra. Para Milton Nascimento, apenas um mero acidente geográfico impediria que os músicos latino americanos fossem considerados como influenciadores de bandas como Beatles:

(...) eu acho o seguinte: numa determinada época, surgiu uma espécie de sentimento musical em várias partes do mundo, muitos tinham mais ou menos a mesma estrela guia. Os arranjos de George Martin, a maneira dos Beatles de cantar, de fazer música, tudo isso tinha muito a ver com o que se fazia em vários outros lugares do mundo, como em Minas Gerais. Era mais uma questão de época do que de influência de um sobre o outro. Acontece que se fosse ao contrário, se a gente tivesse nascido em Liverpool, diriam que a gente teria influenciado os Beatles (NASCIMENTO. In: BUENO, 2008, p. 31).

O contato de artistas e ouvintes brasileiros com o rock inglês pode ser explicado pela difusão dos meios de comunicação midiáticos, que na segunda metade do século XX possibilitam a circulação de informação e bens culturais em maior escala. As antigas limitações de tempo e espaço que inviabilizavam essas trocas agora passam a ser mais dinâmicas e acessíveis: 
À medida que o espaço se encolhe para se tornar uma aldeia "global" de telecomunicações e uma "espaçonave interplanetária" de interdependências econômicas e ecológicas - para usar apenas duas imagens familiares e cotidianas - e à medida em que os horizontes temporais se encurtam até o ponto em que o presente é tudo que existe, temos que aprender a lidar com um sentimento avassalador de compressão de nossos mundos espaciais e temporais (HARVEY. Apud: HALL, 2006, p. 70)

Porém, ainda que possamos assinalar possíveis benesses e facilidades nesse processo de uma suposta "aldeia global", é importante considerarmos a permanência do processo de neocolonização que é fruto da histórica dominação dos países periféricos. Para Silviano Santiago, a dita cultura Ocidental promete abraçar os países latino americanos, desde que eles se comprometam a reiterar as produções da metrópole, permanecendo um passo atrás de todas as tendências nascidas nos grandes centros:

Qual seria a atitude do artista de um país em evidente inferioridade econômica com relação à cultura ocidental, à cultura da metrópole, e finalmente à cultura de seu próprio país? Poder-se-ia surpreender a originalidade de uma obra de arte se se institui como única medida as dívidas contraídas pelo artista junto ao modelo que teve necessidade de importar da metrópole? Ou seria mais interessante assinalar os elementos da obra que marcam a sua diferença? (SANTIAGO, 1978, p. 19)

Santiago primeiro distingue essa diferença ao esmiuçar a visão do senso comum, que a interpreta como fraqueza: de um lado, a produção da neocolônia é chamada por ele de um conjunto de "obras parasitas". Essas seriam fruto de toda uma tentativa de imitar e mimetizar o que é feito nos países do norte. Já as obras de lá são tidas como "a fonte", como criações pioneiras e primordiais. Entre essas duas categorias de valor, existe um espaço simbólico, tão significativo quanto o espaço físico que separa os povos e as obras na geografia real. Em

$$
\text { Jangada | nr. 10, jul/dez, 2017 | ISSN 2317-4722 - 56 | Pág ina }
$$


seguida, ele aborda procedimentos que busquem subverter esse paradigma, recomendando que é necessário "encontrar a escada e contrair a dívida que pode minimizar a distância insuportável entre ele, mortal, e a imortal estrela: tal seria o papel do artista latino-americano, sua função na sociedade ocidental" (SANTIAGO, 1978, p. 20).

Na canção "Para Lennon e McCartney", encontramos um eu-lírico plenamente disposto à tarefa de confrontar tais distâncias. A primeira frase da letra é pura síntese do ethos da canção: "Porque vocês não sabem do lixo ocidental?" (BORGES, BORGES, BRANT, 1970). O dado imediato a ser depreendido de tal verso é o da voz que olha para o velho mundo, e demarca de maneira visceral o espaço entre centro e periferia. Para saber quem são "vocês" basta retornar ao título da canção, que, ao modo epistolar, delimita a priori um destinatário nominal: John Lennon e Paul McCartney, dos Beatles.

Vale relembrar, até mesmo pelas citações já recortadas por nós no presente artigo, que os músicos do Clube da Esquina não nutrem antagonismos pelos Beatles, por seus líderes ou por qualquer artista anglo-saxão do mesmo gênero. O que se interpreta na intenção da canção é a necessidade de falar aos grandes centros irradiadores de cultura - representados metonimicamente pelas figuras de Lennon e McCartney -, apontando simbolicamente para a dinâmica destacada pelo eu-lírico. Se o mundo globalizado que se elabora na segunda metade do século XX permite comunicações tão aceleradas, e um trânsito tão fluido de informações e dados, porque é que a metrópole não consome as culturas periféricas na mesma medida que o oposto acontece? Não deveríamos ser uma "aldeia global" - para retomar a imagem de David Harvey?

Podemos comprovar a pertinência dessa questão até mesmo na contemporaneidade, mais de 35 anos depois do lançamento de "Para Lennon e McCartney. Até 2017, é possível contabilizar oito visitas de Paul McCartney ao Brasil para apresentações musicais, sendo que cinco delas aconteceram entre os anos de 2010 e 2014. Em nenhuma dessas ocasiões recentes (e tampouco em suas visitas anteriores de 1990 e 1993) ele mencionou o Clube da Esquina. Nas redes sociais, um tímido movimento de músicos e fãs tentou fazer com que o clássico disco Clube da Esquina, lançado por Milton Nascimento e Lô Borges em 1971, chegasse às mãos do ex-beatle, mas ao que tudo indica, a iniciativa não obteve êxito.

Nesse caso, é importante mencionar que a canção "Para Lennon e McCartney" não pertence ao disco escolhido para presentear Paul, uma vez que foi lançada no disco anterior, intitulado Milton, de 1970. O disco Clube da Esquina teria sido escolhido pelo fato de ter se 
tornado o trabalho mais emblemático e conhecido desse movimento de músicos mineiros (a ponto de batizar o próprio movimento). Prova da repercussão desse trabalho vem da sua inclusão no livro 1001 discos para se ouvir antes de morrer, de Robert Dimery, que tenta compilar os discos obrigatórios de toda a história da indústria fonográfica, independente da época ou do local de lançamento (DIMERY, 2007).

Por mais que essa repercussão posterior ao lançamento do disco em 1971 faça parecer que o Clube da Esquina encontrou reconhecimento de público e crítica, é inegável que os trabalhos dos músicos brasileiros circulam em um circuito bem mais restrito que o de boa parte dos artistas britânicos do mesmo período. O trânsito deste trabalho se dá em nichos específicos, muito aquém da onipresença dos Beatles em listas de melhores e mais vendidos discos, em relançamentos disponíveis nas lojas especializadas, nas homenagens, nas citações (midiáticas, literárias, etc.), e no papel que ocupam culturalmente em todo o mundo.

Retomamos a análise da canção para abordar o eu-lírico de "Para Lennon e McCartney", que, imbuído de plena potência e autoestima, ignora os estigmas históricos para corajosamente aconselhar aos compositores britânicos: "Não precisam mais temer / Não precisam da solidão / Todo dia é dia de viver" (BORGES, BORGES, BRANT, 1970). De onde vem a confiança com que os compositores latino-americanos, menos conhecidos que os do Norte, dizem para um grupo tão popular que não é preciso nem temer e tampouco precisar da solidão? Porque pensar que os Beatles - constantemente apontados como a maior banda de todos os tempos - são solitários?

É interessante considerar que o eu-lírico tem plena lucidez do processo colonizador em jogo. A expressão "lixo ocidental" é claramente irônica, sobretudo pela segurança com que os destinatários ingleses são confrontados. O eu-lírico foge do estereótipo do "parasita" que Silviano Santiago se refere, e se sente confortável na pele de um sábio, de alguém dotado de experiência - o suficiente para aconselhar e criticar os equívocos dos famosos e célebres músicos do Norte.

Em seu ensaio “O Narrador: considerações sobre a obra de Nikolai Leskov”, Walter Benjamin discute como a figura do narrador e do homem experiente entra em declínio no mundo moderno, uma realidade onde parece equivocado dar conselhos ou pensar que as narrativas podem conter alguma utilidade qualquer. Para Benjamin, a natureza da verdadeira narrativa 
tem sempre em si, às vezes de forma latente uma dimensão utilitária. Essa utilidade pode consistir seja num ensinamento moral, seja numa sugestão pratica, seja num provérbio ou numa norma de vida - de qualquer maneira, o narrador é um homem que sabe dar conselhos. Mas se "dar conselhos" parece hoje algo de antiquado, é porque as experiências estão deixando de ser comunicáveis. Em consequência, não podemos dar conselhos nem a nós mesmos nem aos outros (BENJAMIN, 1993, p. 200).

A crise da experiência na modernidade se dá justamente pela ascensão da informação, que circula mais rápida e em maior quantidade na "aldeia" globalizada. Contudo, não há necessariamente por trás da informação a presença do narrador dotado de experiência, que pode extrair significados e pode selecionar a informação relevante da irrelevante. Para Jorge Larossa Bondía,

A experiência é o que nos passa, o que nos acontece, o que nos toca. Não o que se passa, não o que acontece, ou o que toca. A cada dia se passam muitas coisas, porém, ao mesmo tempo, quase nada nos acontece. Dir-seia que tudo o que se passa está organizado para que nada nos aconteça. Walter Benjamin, em um texto célebre, já observava a pobreza de experiências que caracteriza o nosso mundo. Nunca se passaram tantas coisas, mas a experiência é cada vez mais rara (BONDÍA, 2002, p. 21).

O eu-lírico de "Para Lennon e McCartney" é aquele que percebe a falência da experiência na contemporaneidade, e sua lucidez vem da vivência em um espaço periférico, distante dos grandes centros. Trata-se de um espaço fragmentado, em que a globalização ainda imberbe pode ser notada, e onde convivem elementos modernos e pré-modernos simultaneamente. Nessa geografia contraditória, barroca, desigual, é possível que exista paralelamente (e paradoxalmente) o anacrônico ser da experiência.

A experiência depende das relações de afetos, termo que tomamos como verbo, no sentido de "afetar", e é nessa ação que a experiência se distingue da passividade da informação, 
dos dados meramente racionais. Podemos dizer que a informação está para o mapa assim como a experiência está para o caminho real. Para Larossa Bondía:

\begin{abstract}
A primeira coisa que gostaria de dizer sobre a experiência é que é necessário separá-la da informação. E o que gostaria de dizer sobre o saber de experiência é que é necessário separá-lo de saber coisas, tal como se sabe quando se tem informação sobre as coisas, quando se está informado. É a língua mesma que nos dá essa possibilidade. Depois de assistir a uma aula ou a uma conferência, depois de ter lido um livro ou uma informação, depois de ter feito uma viagem ou de ter visitado uma escola, podemos dizer que sabemos coisas que antes não sabíamos, que temos mais informação sobre alguma coisa; mas, ao mesmo tempo, podemos dizer também que nada nos aconteceu, que nada nos tocou, que com tudo o que aprendemos nada nos sucedeu ou nos aconteceu (BONDÍA, 2002, p. 22).
\end{abstract}

O sujeito da experiência não é solitário, porque ele está aberto para ser afetado. É nesse sentido que o eu-lírico da canção de Lô, Márcio e Fernando enxerga nos homens do Norte a solidão dos que não tem a experiência. Eles que estão lá, nos grandes centros, só tem a si mesmos, enquanto que os da periferia tem a si mesmos mas podem também ser afetados pelos de lá.

Em qualquer caso, seja como território de passagem, seja como lugar de chegada ou como espaço do acontecer, o sujeito da experiência se define não por sua atividade, mas por sua passividade, por sua receptividade, por sua disponibilidade, por sua abertura. Trata-se, porém, de uma passividade anterior à oposição entre ativo e passivo, de uma passividade feita de paixão, de padecimento, de paciência, de atenção, como uma receptividade primeira, como uma disponibilidade fundamental, como uma abertura essencial (BONDÍA, 2002, p. 24). 
Em vez de assumir uma posição ressentida por estar na periferia (e correndo o risco de se enclausurar na mágoa), o eu-lírico não perde de vista a receptividade. Seu movimento é antropofágico, no sentido de respeitar o outro e ao mesmo tempo comungar de sua força - sem que, no processo, sua identidade se torne corrompida, uma vez que nem é possível dizer que se trata de uma identidade fechada e cristalizada.

Eu sou da América do Sul

Eu sei, vocês não vão saber

Mas agora sou cowboy

Sou do ouro, eu sou vocês

Sou do mundo, sou Minas Gerais (BORGES, BORGES, BRANT, 1970).

No espírito repleto de disponibilidade daquele que detém a experiência, é possível ser da América do Sul, e, ao mesmo tempo, vivenciar a vocação de ser um típico "cowboy" do norte. Porque eles de lá "não sabem" tanto quanto sabem os da periferia, que reciclam o lixo ocidental, que vasculham a caçamba atrás de possibilidades de vida e de potência.

É a identidade difusa do ser da experiência que lhe concede este subestimado privilégio. Diferentemente dos que se orgulham de estar no Norte, os sul americanos são tidos lá em cima como "estrangeiros", da mesma forma que os gregos intitulavam como "bárbaros" todos aqueles que não possuíam sua nacionalidade. Larossa Bondía nos esclarece que, na própria etimologia da palavra "experiência", está inscrita também a dimensão do desterrado, do estrangeiro, do que se encontra em um espaço alheio ao centro:

A palavra experiência vem do latim experiri, provar (experimentar). A experiência é em primeiro lugar um encontro ou uma relação com algo que se experimenta, que se prova. O radical é periri, que se encontra também em periculum, perigo. A raiz indo-européia é per, com a qual se relaciona antes de tudo a ideia de travessia, e secundariamente a ideia de prova. Em grego há numerosos derivados dessa raiz que marcam a travessia, o percorrido, a passagem: peirô, atravessar; pera, mais além; peraô, passar 
através, perainô, ir até o fim; peras, limite. (...) A palavra experiência tem o ex de exterior, de estrangeiro, de exílio, de estranho e também o ex de existência. A experiência é a passagem da existência, a passagem de um ser que não tem essência ou razão ou fundamento, mas que simplesmente "ex-iste" de uma forma sempre singular, finita, imanente, contingente (BONDÍA, 2002, p. 25).

É esse ser que "não tem essência ou razão ou fundamento" que consegue, a um só tempo, ser e não ser de sua terra. Ou, melhor dizendo, afirmar na mesma frase que é do mundo e é "Minas Gerais". A palavra "travessia", em especial, merece uma menção à parte, por batizar o primeiro grande sucesso de Milton Nascimento, de 1967, e também por ter outro elo para além da música, marcando uma obra igualmente universal e mineira que é Grande Sertão: Veredas, de Guimarães Rosa. O longo épico se passa em um sertão simultaneamente calcado no real e na imaginação (sendo que na parcela "real" de sua dimensão, se refere ao norte de Minas Gerais), e é fortemente marcado pelo signo da ambiguidade. A última palavra do romance, longe de implicar em um fechamento da narrativa, deixa clara a sua abertura intransitiva: travessia. A mesma palavra que fecha a obra rosiana abre a carreira de Milton e, consequentemente, do Clube da Esquina. Ambos, filhos das Gerais, constroem sua estética através do arquétipo da experiência.

O homem experiente, alerta Bondía, não é livre da dor da inconstância. E justamente por esse motivo é que ele se torna capaz de aconselhar ao inexperiente que não é preciso ter medo e nem timidez. É da própria experiência dolorida que surge a consciência de que não vale a pena insistir em tais errâncias. É através do processo de travessia pela dor e de sua superação/sublimação que ressurge a certeza de que "todo dia é dia de viver".

O sujeito da experiência (...) é um sujeito alcançado, tombado, derrubado. Não um sujeito que permanece sempre em pé, ereto, erguido e seguro de si mesmo; não um sujeito que alcança aquilo que se propõe ou que se apodera daquilo que quer; não um sujeito definido por seus sucessos ou por seus poderes, mas um sujeito que perde seus poderes precisamente porque aquilo de que faz experiência dele se apodera. Em contrapartida, o sujeito da experiência é também um sujeito sofredor, padecente, receptivo, aceitante, interpelado, submetido. Seu contrário, o sujeito incapaz de 


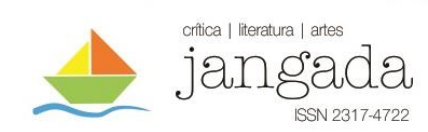

experiência, seria um sujeito firme, forte, impávido, inatingível, erguido, anestesiado, apático, autodeterminado, definido por seu saber, por seu poder e por sua vontade (BONDÍA, 2002, p. 25).

Não à toa, Silviano Santiago diz que as leituras do escritor latino-americano "não são nunca inocentes. Nunca poderiam sê-lo" (SANTIAGO, 1978, p. 24). Ele não se acomoda nas informações. Porque, diferente do sujeito da informação, ele não é apático e repleto de saber acumulado. Desde a formação do povo brasileiro, tínhamos, de um lado, os missionários dotados da palavra sagrada, do saber instituído; e, de outro, os índios que clamavam por uma "representação dos acontecimentos narrados oralmente", e, incapazes de aceitar passivamente o saber abstrato, recusavam a transformar a palavra em escritura (SANTIAGO, 1978, p. 15).

Larossa Bondía diz que "é experiência aquilo que 'nos passa', ou que nos toca, ou que nos acontece, e ao nos passar nos forma e nos transforma. Somente o sujeito da experiência está, portanto, aberto à sua própria transformação" (BONDÍA, 2002, p. 26). É assim que o eulírico de "Para Lennon e McCartney" pode, em um passe de mágica, tornar-se cowboy, ser ao mesmo tempo "do ouro" de Minas e ser "vocês" - ser da sua terra e da outra, ser grego e ao mesmo tempo bárbaro, ser do mundo e ser Minas Gerais.

A territorialidade do sujeito da experiência funciona em outra chave de compreensão, como um fantasma na máquina, como uma sombra na civilização ocidental, operando "com" e ao mesmo tempo "sem" o lastro da tradição secularizada. Afinal, se o eu-lírico percebe seu "lado ocidental" na herança de seu dominador, ele também reconhece-se como "lixo ocidental", sabendo que em sua face persiste a "letra escarlate" deixada pelos que um dia o colonizaram. Assim como a personagem Hester Prynne no romance de Nathaniel Hawthorne, o latinoamericano sabe que pode caminhar pelas ruas da "Salem ocidental", mas nunca será um membro plenamente respeitado.

Assim, ele é obrigado a criar um "contra-espaço", onde duplica e amplifica o legado do colonizador. Santiago esclarece que "pelo extermínio constante dos traços originais, pelo esquecimento da origem, o fenômeno da duplicação se estabelece como a única regra válida de civilização" (SANTIAGO, 1978, p. 17). Vítima do apagamento das raízes que um dia lhe deram a sensação de pertencimento, a mera existência do cidadão da América do Sul lembra o europeu de que os conceitos de "unidade" e "pureza" são mera abstração retórica. Na duplicação fracassada da matriz colonizadora, está o trunfo da vocação desviante, do movimento "ativo e

$$
\text { Jangada | nr. 10, jul/dez, } 2017 \text { | ISSN 2317-4722 - 63 | P á g i n a }
$$


destruidor, que transfigura os elementos feitos e imutáveis que os europeus exportavam para o novo mundo" (SANTIAGO, 1978, p. 18).

Assim, "Para Lennon e McCartney" não apenas se vale de um contundente conteúdo lírico, mas se dá ao luxo de emular uma perfeita sonoridade dos artistas britânicos, se tomarmos como referência os arranjos da versão original interpretada por Milton Nascimento e pela banda Som Imaginário em 1970. Mostra, assim, que aquela sonoridade não era privilégio da metrópole. Seja pelos riffs cativantes de Zé Rodrix, pelos teclados tecnicamente fantásticos de Wagner Tiso ou pela voz inigualável de Milton Nascimento, seria difícil dizer que essa música passaria em branco nas paradas de sucesso de semanários estrangeiros como a Billboard ou a The Melody Maker - exceto pelo fato de ser uma música latino-americana.

Por tudo isso, podemos pensar em "Para Lennon e McCartney" como uma espécie de “canção postal” (espirituosa expressão que batizaria uma faixa do primeiro disco solo de Lô Borges), endereçada não apenas aos dois Beatles citados, mas aos grandes centros da indústria cultural. Podemos ouvir ali a voz ancestral da autêntica experiência, "essa rede que se desfaz hoje por todos os lados, depois de ter sido tecida, há milênios, em torno das mais antigas formas de trabalho manual" (BENJAMIN, 1993, p. 205).

A condição especial do Brasil, país periférico, urbano e rural a um só tempo, foi um dos aspectos que permitiu a seus criadores e artistas vislumbrar diferentes panoramas, e que lhes legou como característica especial a capacidade de se desviar da norma, parodiá-la, subvertela. Assim, foi possível a eles desenvolver uma marca fluida de identidade, possível de ser apreciada sem nenhum demérito de valor ético ou estético em relação ao que é produzido em outras partes do mundo.

\section{REFERÊNCIAS BIBLIOGRÁFICAS}

BENJAMIN, Walter. Magia e técnica, arte e política. São Paulo: Brasiliense, 1993.

BONDÍA, Jorge Larossa. Notas sobre a experiência e o saber de experiência. In: Revista Brasileira de Educação. № 19. Rio de Janeiro: Anped, janeiro/ abril de 2002.

BORGES, Lô; BORGES, Márcio; BRANT, Fernando. Para Lennon e McCartney. In: NASCIMENTO, Milton. Milton. EMI Odeon: 1970.

BORGES, Márcio. Os sonhos não envelhecem - Histórias do Clube da Esquina. São Paulo: Geração Editorial, 2004. 
BUENO, Andréa dos Reis Estanislau. Coração Americano: 35 anos do álbum Clube da Esquina. Andréa Estanislau (org.). Belo Horizonte: Prax, 2008.

DIMERY. Robert. (Org.) 1001 discos para ouvir antes de morrer. Rio de Janeiro: Sextante, 2007.

HALL, Stuart. A identidade cultural na pós-modernidade. Rio de Janeiro: DP\&A, 11a ed., 2006.

SANTIAGO, Silviano. O entre-lugar do discurso latino-americano. In: Uma literatura nos trópicos: ensaios sobre dependência cultural. São Paulo: Perspectiva, 1978. 